\title{
Giant aneurysm of the ascending aorta
}

\author{
Vivek Srivastava, ${ }^{1}$ Kenda AlHadid, ${ }^{1}$ P Saravanan, ${ }^{2}$ J Zacharias, ${ }^{1}$ M N Bittar ${ }^{1}$
}

1Department of Cardiothoracic Surgery, Victoria Hospital, Blackpool, UK;

2Department of Cardiothoracic Anaesthesia, Victoria Hospital, Blackpool, UK

Correspondence to Vivek Srivastava, srivivek50@hotmail.com

\section{Summary}

An ascending aortic aneurysm is a rare entity. The authors encountered an 85-year-old female patient with an uncomplicated ascending aortic aneurysm measuring $9 \mathrm{~cm}$ in diameter. She underwent an urgent operation involving replacement of the ascending aorta. Postoperatively, she developed mild renal failure and atrial flutter requiring direct current cardioversion. However, further recovery was good. The authors present this case including the operative management and a brief overview of this rare condition to reiterate that with an ageing population, this procedure can be done with an acceptable morbidity.

\section{BACKGROUND}

An ascending aortic aneurysm is a rare entity. The patient we report here was 85-year-old and was found to have an ascending aortic aneurysm measuring $9 \mathrm{~cm}$ which was uncomplicated at diagnosis. She underwent a successful surgery which demonstrates that complex cardiac surgery is becoming safer despite an older population.

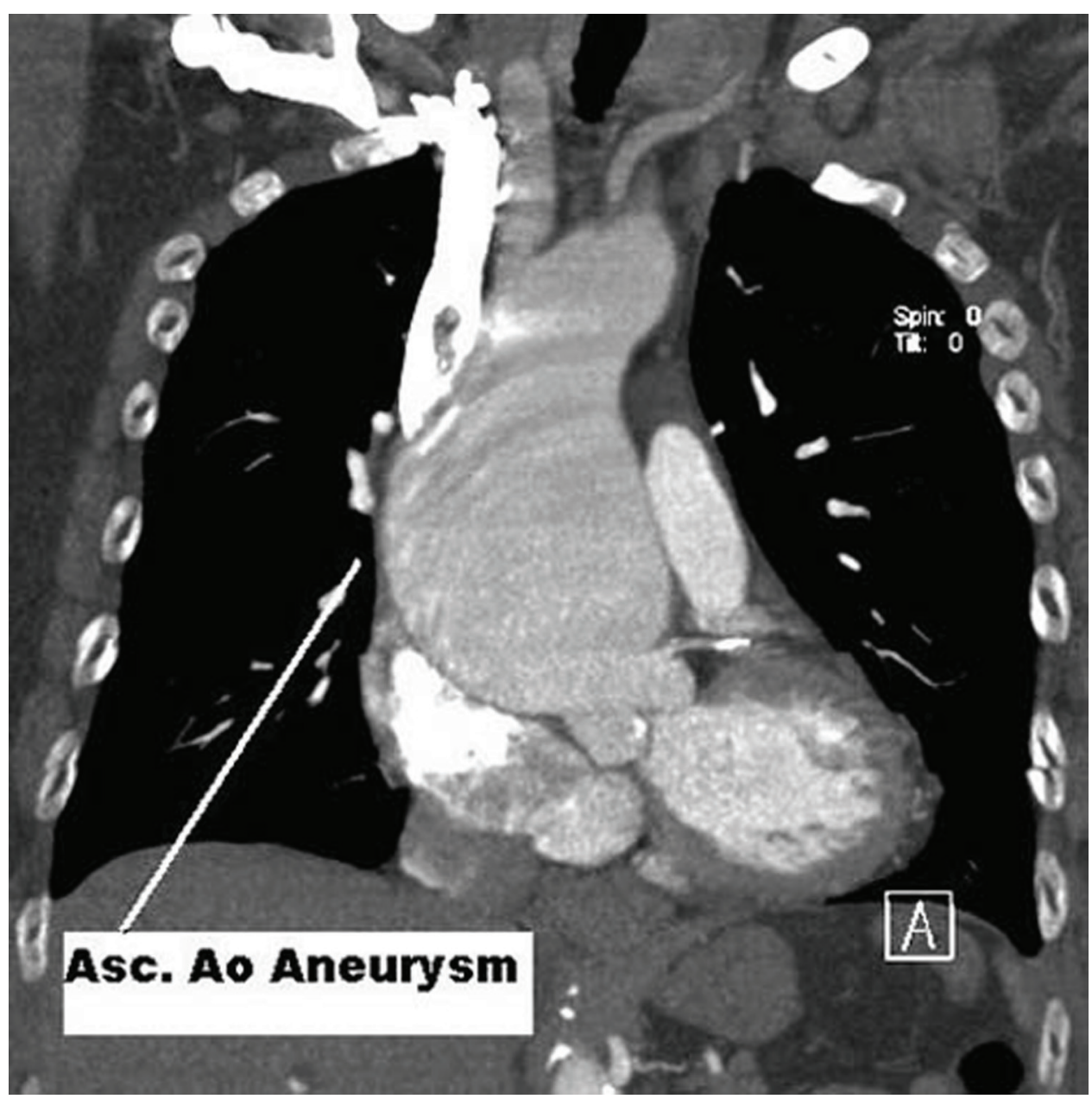

Figure 1 CT scan coronal section showing the ascending aortic aneurysm. 


\section{BMJ Case Reports}

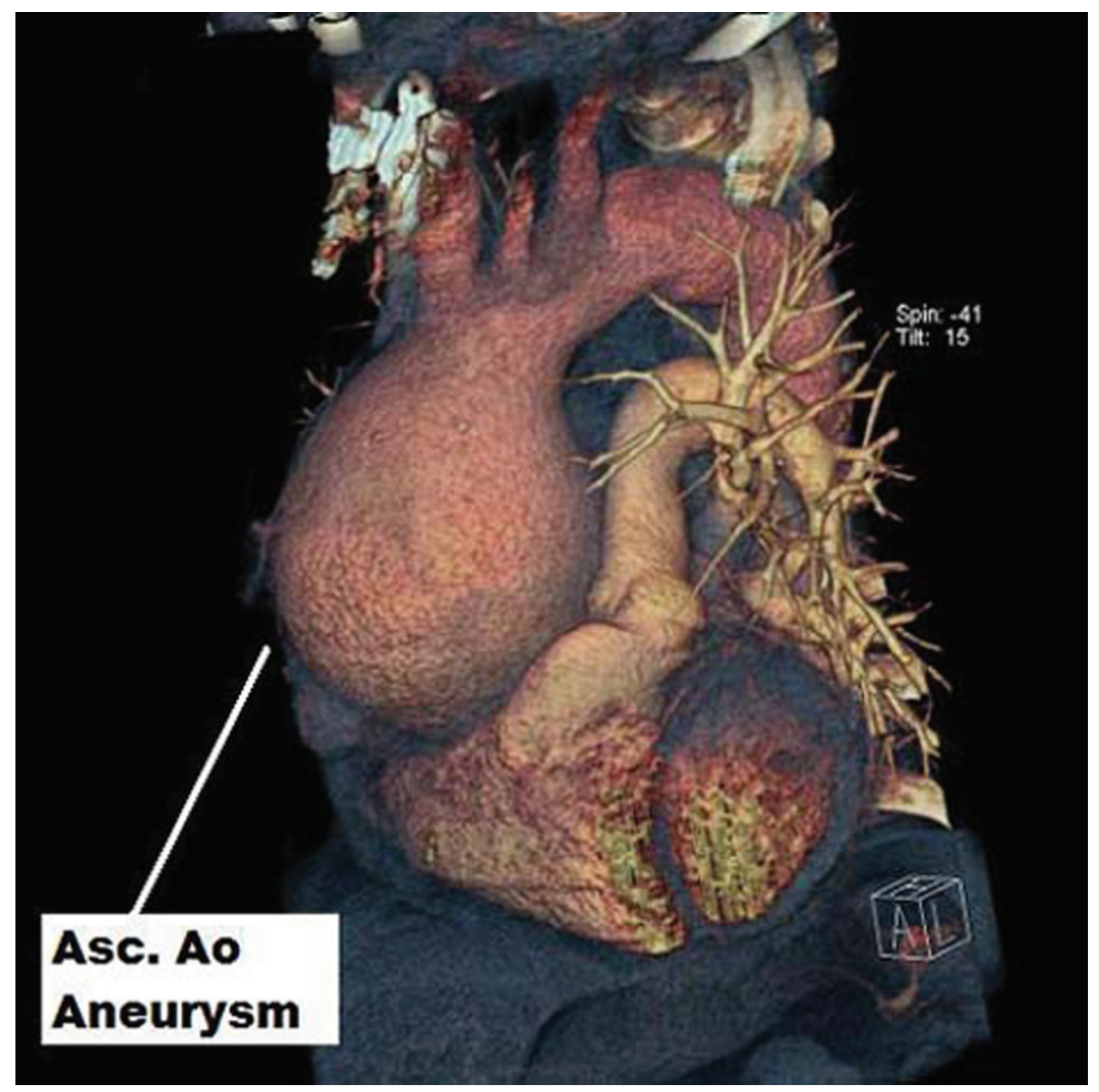

Figure 2 CT reconstructed 3D image demonstrating the massively enlarged ascending aorta.

\section{CASE PRESENTATION}

An 85-year-old female presented with complaints of recurrent cough of approx 2-month duration and shortness of breath on exertion equating to NYHA (New York Heart Association) Class II. Comorbidities included mild asthma and a lumbar spine fracture resulting from osteoporosis.

\section{INVESTIGATIONS}

A chest X-ray showed a dilated ascending aorta. She had a CT aortography which showed gross dilatation of the ascending aorta with no evidence of dissection (figures 1 and 2). The mid-ascending aorta at the level of the pulmonary trunk bifurcation was measured to be $9 \mathrm{~cm}$ ! Aortic root was normal with the dilatation starting only above the sinotubular junction and extending up to the proximal arch of aorta. The CT scan also revealed significant calcification in the right common femoral artery. She underwent a coronary angiogram on the day of surgery which revealed mild coronary disease.

\section{TREATMENT}

\section{Operation}

Perioperative anaesthetic preparation included general anaesthesia, insertion of central venous and arterial lines and a transoesophageal echo (TOE) probe. TOE revealed only mild aortic regurgitation, hence it was decided to conserve the aortic valve. The left common femoral vessels were exposed and cannulated to establish cardiopulmonary bypass. Median sternotomy was then performed. Pericardiotomy revealed a very large ascending aortic aneurysm extending from the sinotubular junction to the base of the arch of aorta. Dissection was carried out around the arch to free the entire ascending aorta and the arch of aorta and to separate the innominate vein. The aorta was clamped across the arch. Systemic cooling was commenced to achieve a temperature of $30^{\circ} \mathrm{C}$. Simultaneously cardioplaegia was delivered through the aortic root with prompt cardiac arrest. Aortotomy was made and the ascending aorta was excised. After sizing the sinotubular junction, a size $30 \mathrm{~mm}$ Dacron tube graft was used to replace the ascending aorta using 4-0 Prolene sutures supported by Teflon strips. The proximal anastomosis was made at the sinotubular junction whereas distally, the graft was anastomosed to the concavity of the arch of aorta. Extensive deairing was then performed and the cross clamp was released. The heart resumed in normal sinus rhythm. The patient was rewarmed and cardiopulmonary bypass was weaned off uneventfully. She remained stable in the intensive care unit and was extubated shortly afterwards. 


\section{OUTCOME AND FOLLOW-UP}

Recovery was complicated by mild renal impairment which resolved with conservative management. She also developed atrial flutter for which she required direct current cardioversion. Further postoperative course was uneventful and the patient was discharged home on the eighth postoperative day. She had a follow-up appointment at 6 weeks at which she had completely recovered from her operation.

\section{DISCUSSION}

The exact incidence of thoracic aortic aneurysms (TAA) is unknown but has been reported as 16.3 per 100000 per year for men and 9.1 per 100000 per year for women. ${ }^{1}$ The incidence increases with age and the prevalence has been estimated to be increasing over the years. ${ }^{1}$ Approximately $60 \%$ of TAAs involve the ascending aorta or aortic root. ${ }^{2}$ Pathologically, the most common cause of these aneurysms is cystic medial necrosis. The most common factor in the younger population is Marfan syndrome or a bicuspid aortic valve which may be associated with aortic pathology. However, in the older population, arteriosclerotic degeneration is the most common cause. Other causes include trauma, aortic pseudoaneurysms, aortic dissection and various forms of arteritis (including Takayasu's arteritis, giant-cell arteritis and the now uncommon syphilis). Most commonly ascending aortic aneurysms are asymptomatic and are discovered as an incidental finding on chest imaging. However, larger aneurysms can present with symptoms resulting from compression of surrounding structures including the trachea/bronchi and the oesophagus. They can result in hoarseness from recurrent laryngeal nerve paralysis and chest pain or back pain. They have also been reported as a rare cause for the superior vena cava syndrome. ${ }^{3}$ Associated enlargement of the aortic root can lead to aortic regurgitation. Large aneurysms can present with aortic dissection or rupture into pericardium leading to cardiac symptoms (collectively called acute aortic syndrome). Imaging modalities to aid diagnosis and management include contrast enhanced CT scan, MR angiogram and echocardiography. The aneurismal thoracic aortic size increases at an average rate of $0.1 \mathrm{~cm} /$ year $^{4}$ which determines the natural history. In a study of 1600 patients, Elefteriades ${ }^{4}$ found that the incidence of complications increased sharply at an aortic size of $6 \mathrm{~cm}$ at which point $31 \%$ of patient had suffered rupture or dissection. The current American Heart Association guidelines, ${ }^{5}$ therefore, recommend that asymptomatic patients with degenerative thoracic aneurysm, chronic aortic dissection, intramural haematoma, penetrating atherosclerotic ulcer, mycotic aneurysm or pseudoaneurysm, who are otherwise suitable candidates and for whom the ascending aorta or aortic sinus diameter is $5.5 \mathrm{~cm}$ or greater, should be evaluated for surgical repair. However, patients with Marfan syndrome or other genetically mediated disorders (vascular EhlersDanlos syndrome, Turner syndrome, bicuspid aortic valve or familial TAA and dissection) should undergo elective operation at smaller diameters $(4.0-5.0 \mathrm{~cm}$ depending on the condition to avoid acute dissection or rupture. In addition, Patients with symptoms suggestive of expansion of a thoracic aneurysm should be evaluated for prompt surgical intervention unless life expectancy from comorbid conditions is limited or quality of life is substantially impaired. Elective surgery for ascending aortic aneurysms at large and experienced centres involves a mortality of $3-7 \%{ }^{6}$

\section{Learning points}

- In the present case, the patient was fortunate enough to have a very large ascending aortic aneurysm diagnosed before a catastrophic event. There are few reports of an ascending aortic aneurysms presenting at this size without a complication

- Although she was 85-year-old, she had a good quality of life and wished to proceed with surgery in spite of the high risk

- She underwent a successful operation with very satisfactory recovery

- Cardiac surgery is pushing boundaries and becoming safer despite an ageing population and that in days to come will result in improved longevity.

\section{Competing interests None}

Patient consent Obtained

\section{REFERENCES}

1. Olsson C, Thelin S, Stăhle E, et al. Thoracic aortic aneurysm and dissection: increasing prevalence and improved outcomes reported in a nationwide population-based study of more than 14,000 cases from 1987 to 2002. Circulation 2006;114:2611-18.

2. Isselbacher EM. Thoracic and abdominal aortic aneurysms. Circulation 2005;111:816-28.

3. Fukui T, Ro D, Takanashi S. Superior vena cava syndrome secondary to chronic dissecting aortic aneurysm after aortic valve replacement. Interact Cardiovasc Thorac Surg 2010;11:192-3.

4. Elefteriades JA. Natural history of thoracic aortic aneurysms: indications for surgery, and surgical versus nonsurgical risks. Ann Thorac Surg 2002;74:S1877-80; discussion S1892-8.

5. Hiratzka LF, Bakris GL, Beckman JA, et al. 2010 ACCF/AHA/AATS/ACR/ ASA/SCA/SCAI/SIR/STS/SVM Guidelines for the diagnosis and management of patients with thoracic aortic disease. A Report of the American College of Cardiology Foundation/American Heart Association Task Force on Practice Guidelines, American Association for Thoracic Surgery, American College of Radiology, American Stroke Association, Society of Cardiovascular Anesthesiologists, Society for Cardiovascular Angiography and Interventions, Society of Interventional Radiology, Society of Thoracic Surgeons, and Society for Vascular Medicine. J Am Coll Cardiol 2010;55:e27-e129.

6. Evangelista A. Aneurysm of the ascending aorta. Heart 2010;96:979-85. 


\section{BMJ Case Reports}

This pdf has been created automatically from the final edited text and images.

Copyright 2011 BMJ Publishing Group. All rights reserved. For permission to reuse any of this content visit http://group.bmj.com/group/rights-licensing/permissions.

BMJ Case Report Fellows may re-use this article for personal use and teaching without any further permission.

Please cite this article as follows (you will need to access the article online to obtain the date of publication).

Srivastava V, AlHadid K, Saravanan P, Zacharias J, Bittar MN. Giant aneurysm of the ascending aorta. BMJ Case Reports 2011:

10.1136/bcr.11.2010.3504, date of publication

Become a Fellow of BMJ Case Reports today and you can:

- Submit as many cases as you like

- Enjoy fast sympathetic peer review and rapid publication of accepted articles

- Access all the published articles

- Re-use any of the published material for personal use and teaching without further permission

For information on Institutional Fellowships contact consortiasales@bmjgroup.com

Visit casereports.bmj.com for more articles like this and to become a Fellow 